\title{
A Review of Chile Pepper (Capsicum annuum) Stip: A Physiological Disorder of Peppers
}

\author{
James C. Fulton ${ }^{1}$ \\ Plant and Environmental Sciences, New Mexico State University, Las \\ Cruces, NM 88003
}

\author{
Mark E. Uchanski ${ }^{2,3}$ \\ Horticulture and Landscape Architecture, Colorado State University, Fort \\ Collins, CO 80523-1173
}

Additional index words. abiotic disorder, environmental stress, bell, chile

\begin{abstract}
Stip, a physiological disorder, which affects certain pepper (Capsicum annuum) cultivars and pod types, has received limited formal academic attention. The disorder, frequently noted for its appearance in bell peppers, but also present in pimento and New Mexican pod types, has been attributed in the literature to nutrient imbalances and/or temperature extremes. Symptoms of this disorder present on fully developed fruits as brown, black, and yellow ovoid subcutaneous chlorotic lesions $\approx 1.3 \mathrm{~cm}$ in length and $0.6 \mathrm{~cm}$ in width extending from the endocarp to the mesocarp, without apparent expression in the cuticle. Chile pepper has been significantly affected by stip for the past several decades leading to varying degrees of commercial losses. Due to the sporadic and seemingly spontaneous nature of the disorder, prolonged research interest has not been sustained. This review provides the reader a comprehensive synthesis of all available literature regarding this physiological disorder. Especially because research into this disorder is scarce, it is essential that any and all previous research be made available together in one document to interested scientists, breeders, and growers. To achieve this goal, all available stip-related publications were obtained and analyzed; additionally, searches were performed using all names associated with the disorder. The literature suggests that stip manifestation is a consequence of an interaction between a genetic component (open-pollinated cultivars being more susceptible to symptom expression than hybrids) and an environmental component (increased nitrogen application, shading, and soil applications of lime appear to increase both severity and incidence).
\end{abstract}

The terms "stip" (Smith et al., 1996, 1997, 1998), "black spot" (Villalon, 1975), "colour spots" (Aloni et al., 1994; Feigin and Sagiv, 1987), "green spotting" (Carroll, 1979), "green pitting" (Hibberd, 1981), "spotting” (Uffelen, 1973, 1975), "bitter pit” (Eijsinga et al., 1973), and "pepper spot" (Stolk and Maaswinkel, 1977) are different names that have been used in the literature to describe what is likely the same physiological disorder of peppers. This disorder, hereafter referred to as stip, was independently described twice in the 1970s, once in the Netherlands and once in Texas (Eijsinga et al., 1973; Villalon, 1975). Stip symptoms have been described most extensively in bell peppers (Aloni et al., 1994; Carroll, 1979; Eijsinga et al., 1973; Feigin and Sagiv, 1987; Hibberd, 1981; Smith et al.,

Received for publication 5 July 2016. Accepted for publication 12 Oct. 2016.

Funding for this research was provided by the New Mexico Chile Association. Additional salaries and research support were provided by state and federal funds appropriated to the New Mexico Agricultural Experiment Station.

${ }^{1}$ Graduate Research Assistant.

${ }^{2}$ Assistant Professor.

${ }^{3}$ Corresponding author. E-mail: mark.uchanski@ colostate.edu. results to interested readers, not only of academic interest but commercial as well. This review should facilitate advances toward a deeper understanding of the disorder leading to effective treatments and additional preventive measures instead of repeating previously conducted, yet difficult to obtain, studies.

\section{Description of Lesions}

Symptoms of stip appear as pale to dark green (Eijsinga et al., 1973; Hibberd, 1981; Smith et al., 1996, 1997, 1998), yellow (Aloni et al., 1994; Feigin and Sagiv, 1987; Smith et al., 1996, 1997, 1998), or black (Smith et al., 1996, 1997, 1998; Villalon, 1975) lesions in pepper pod tissue. Affected tissue may be sunken (Eijsinga et al., 1973; Feigin and Sagiv, 1987; Hibberd, 1981; Villalon, 1975), oval or irregularly shaped (Hibberd, 1981; Villalon, 1975). Chlorotic or necrotic areas of pod wall cells (Hibberd, 1981; Villalon, 1975) have been reported as between 1 and $10 \mathrm{~mm}$ in diameter (Eijsinga et al., 1973; Feigin and Sagiv, 1987; Hibberd, 1981; Smith et al., 1996, 1997, 1998; Villalon, $1975)$, however, observed by the author as between 5 and $15 \mathrm{~mm}$ in southern New Mexico, that extend throughout the exocarp and mesocarp (Fig. 1).

Lesions may also have a soft to dry texture (Villalon, 1975). The severity (number of lesions per symptomatic pod) may vary between 1 and 30 (Eijsinga et al., 1973; Feigin and Sagiv, 1987; Hibberd, 1981; Smith et al., 1996, 1997, 1998; Villalon, 1975). Except for these lesions, the vegetative and reproductive portions of plants appear normal (Villalon, 1975).

\section{Description of Symptom Manifestation}

1996, 1997, 1998; Stolk and Maaswinkel, 1977; Uffelen, 1973, 1975; Villalon, 1975); however, pimento, and New Mexican pod-type peppers have also been mentioned (Smith et al., 1995, 1996, 1997, 1998; Villalon, 1975; Table 1).

Previous studies have attempted to establish that stip is not a consequence of any known virus, bacterium, or fungus (Eijsinga et al., 1973; Hibberd, 1981; Smith et al., 1996; Villalon, 1975), and no insect damage is reported in connection with this disorder (Eijsinga et al., 1973; Hibberd, 1981; Villalon, 1975). Consequently, symptoms are believed to be a manifestation of a physiological disorder (Aloni et al., 1994; Carroll, 1979; Eijsinga et al., 1973; Feigin and Sagiv, 1987; Hibberd, 1981; Smith et al., 1996, 1997; Stolk and Maaswinkel, 1977; Uffelen, 1973, 1975; Villalon, 1975). The disorder has been sporadically reported in geographically distant academic journals over the past 40 years, likely because it presents as a problem in a given production area for brief, and apparently random times. As a result, there has not been sustained and focused attention on studying the condition. Therefore, a comprehensive review that consolidates the information generated through these spatially and temporally disparate studies can be useful to describe, synthesize, and present previous research
Stip symptom development has been observed in the greenhouse (Aloni et al., 1994; Carroll, 1979; Eijsinga et al., 1973; Stolk and Maaswinkel, 1977) as well as under field conditions (Feigin and Sagiv, 1987; Hibberd, 1981; Smith et al., 1996, 1997, 1998; Villalon, 1975), and its severity and incidence have been reported as variable from year to year and therefore difficult to predict (Eijsinga et al., 1973; Smith et al., 1996, 1997, 1998; Villalon, 1975). Although the disorder has been reported as most pronounced when pods are fully mature and red in color (Feigin and Sagiv, 1987; Hibberd, 1981; Smith et al., 1996, 1997, 1998), the disorder has also been noted when pods are mature green, with symptoms becoming more apparent as they mature further (Aloni et al., 1994; Villalon, 1975). Consequently, symptoms are most often noted during harvest in the late summer and early fall transition period oftentimes occurring when nights are cool, daylength is shorter, and dews are heavy for fall harvested peppers (Aloni et al., 1994; Eijsinga et al., 1973; Feigin and Sagiv, 1987; Hibberd, 1981; Smith et al., 1996, 1997, 1998; Villalon, 1975; Wien and Zitter, 2003). Increased symptom severity and incidence have been described during the middle portion of 
Table 1. A summary of the published literature referencing the physiological disorder known as stip in peppers, arranged alphabetically by author

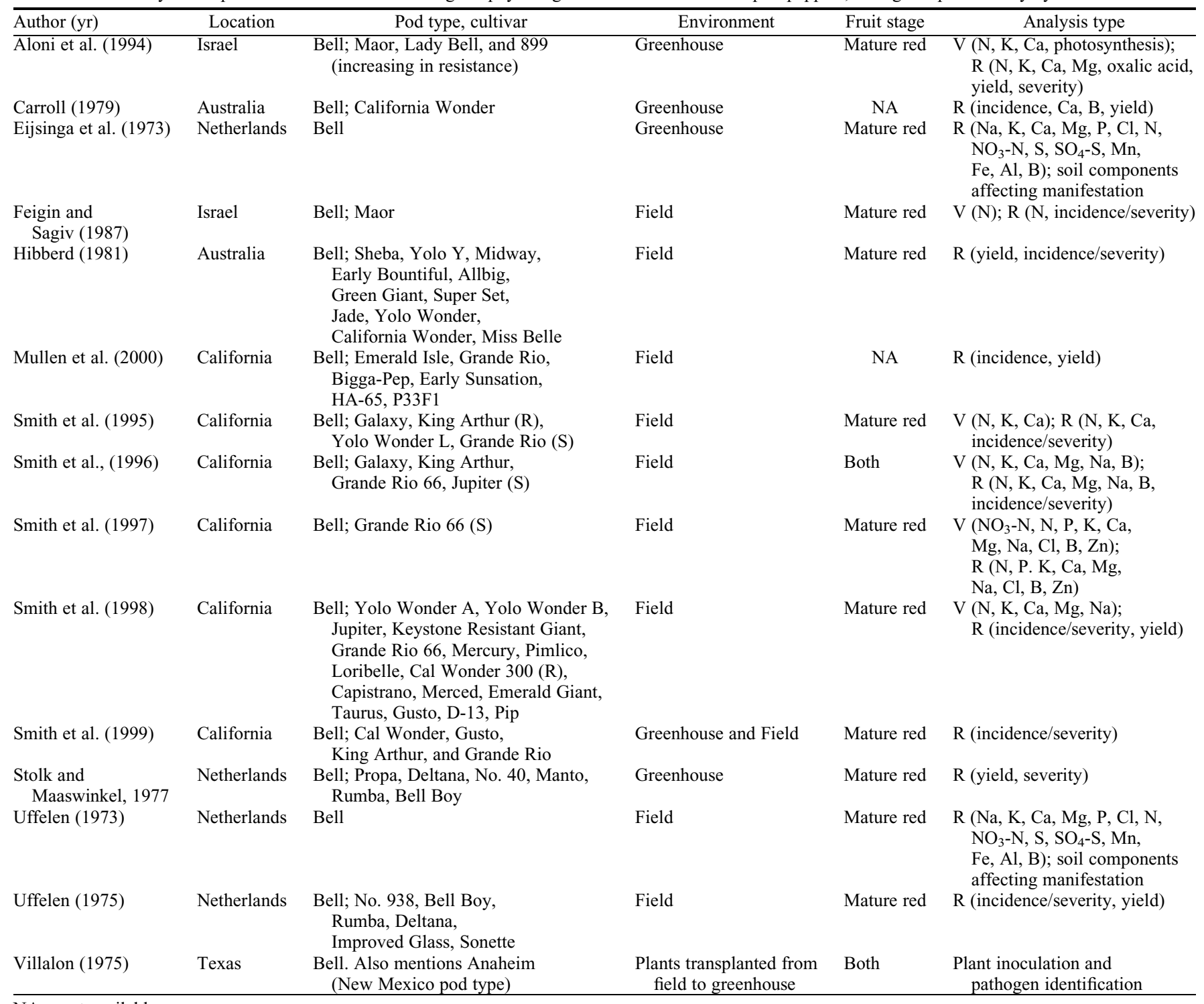

NA $=$ not available.

${ }^{2}$ Known susceptibility $(\mathrm{S})$ or resistance $(\mathrm{R})$ is annotated in the cultivar column.

y Tissue type tested, vegetative $(\mathrm{V})$ or reproductive $(\mathrm{R})$, and the data collected are annotated in the appropriate column.

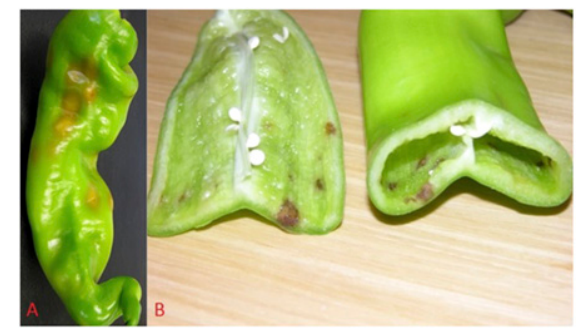

Fig. 1. Stip symptom expression. (A) Stip symptoms in a New Mexican pod-type pepper in the field. (B) Affected tissue extends through the depth of the mesocarp and exocarp while the cuticle remains asymptomatic (photo credit: Dr. Stephanie Walker).

harvest, about late August to mid-September in the Northern Hemisphere (B. Etcheverry, personal communication), with decreasing severity and incidence as the season progresses, to after mid-September (B. Etcheverry, personal communication; Hibberd, 1981). Commercial losses have not been formally quantified (Carroll, 1979; Eijsinga et al., 1973; Feigin and Sagiv, 1987; Hibberd, 1981; Smith et al., 1996, 1997, 1998; Villalon, 1975), but cull rates associated with stip were $25 \%$ in a study by Hibberd (1981) and severity reached $67 \%$ of total fruit in a separate field study by Feigin and Sagiv (1987).

\section{Genetic Differences}

Several researchers have reported differences among cultivars in their susceptibility to symptom manifestation (Aloni et al., 1994; Hibberd, 1981; Smith et al., 1996; Stolk and Maaswinkel, 1977). Furthermore, openpollinated cultivars have been described as more susceptible to the disorder (Smith et al., 1996, 1997, 1998) as compared with hybrids, which are described as having moderate to full resistance (North Carolina State University,
1996; Seminis, 2015; Smith et al., 1996, 1997, 1998, 1999). Consequently, Smith et al. (1996, 1997, 1998, 1999) have suggested that although they may be more expensive, improved hybrid cultivars may be the most effective strategy for limiting stip impact especially if the cost for improved genetics can be recouped through improved fruit quality or other cost-saving mechanisms.

Furthermore, researchers have included the possibility that the genetic factors contributing to differences between susceptibility, and resistance might be related to the yield and fruit size differences found among these cultivars (Eijsinga et al., 1973; Feigin and Sagiv, 1987; Hibberd, 1981; Table 2).

For example, Feigin and Sagiv (1987) described the possible relationship between larger fruits, the anatomical structure of the pod vascular tissue, and stip symptom manifestation. Their research suggested a possible relationship between large pods with 
small vascular tissue as a possible contributing factor because these pods may be more prone to water transport challenges. Subsequently, any addition of biotic or abiotic stresses may increase manifestation of stip lesions. Furthermore, in Australia under field conditions, Hibberd reported a statistically significant $(P<0.05)$ correlation $(r=$ 0.48 ) between the number of lesions present on a bell fruit and the weight of the fruit (Hibberd, 1981).

Additionally, the possible relationship between fruit size, yield, and increased incidence and severity may be supported by the findings of Smith et al. (1996) who has reported that stip-resistant bell pepper cultivars significantly out-yielded susceptible cultivars. Resistant cultivars Galaxy and King Arthur yielded 66.55 and 52.6 tons of mature green and red pods per hectare with average fruit weights of 218.1 and $223.7 \mathrm{~g}$, respectively, compared with susceptible cultivars Grande Rio and Jupiter, which yielded 37.35 and 30.93 tons of mature green and red pods per hectare with average fruit weights of 204.7 and $182.05 \mathrm{~g}$, respectively. A possible explanation for this association could be that cultivars bred for higher yields and fruit masses have indirectly retained traits for wider xylem diameter tissue. Hence, cultivars with lower yields and/or fruit mass may be more prone to stip manifestation if grown under heavy fertilization rates as their inherent vascular tissue is not adequate to compensate for increased fruit size and yield. However, the directionality of a relationship between fruit anatomy and stip expression, if one indeed exists, is unclear. Although Villalon (1975) reported that "fruit size, shape, and yield do not seem to be affected by black spot," it is possible that incidence and severity may be a consequence of the yield and/or fruit weight.

Lastly, Aloni et al. published results from an experiment in Israel using the bell peppers 'Maor', 'Lady Bell', and '899'. These peppers were chosen because they vary in stip susceptibility in decreasing order with ' 899 ' showing complete resistance. Individual plant yield values within the control treatment (grown in fully lighted conditions with no fertilizer application) increased sequentially. 'Maor', the most susceptible, had a yield of $376 \mathrm{~g}$, whereas '899' yielded 436 g per plant. Furthermore, the average fruit weight for 'Maor' was $86 \mathrm{~g}$, whereas ' 899 ' produced average pods weighing $117 \mathrm{~g}$ (Aloni et al., 1994). In addition to the possibility of a genetic basis implied by the aforementioned differences between cultivar's susceptibility, yield, and fruit weight, several researchers have shown that normally tolerant or resistant cultivars can express symptoms given certain environmental conditions such as temperature, amount of nitrogen fertilization, soil constituents, and planting distance, suggesting a genetic/environmental interaction (Aloni et al., 1994; Carroll, 1979; Eijsinga et al., 1973; Feigin and Sagiv, 1987; Smith et al., 1997).

\section{Environmental Growing Conditions}

Several studies have reported that environmental conditions can be determinants in the development of symptoms (Aloni et al., 1994; Carroll, 1979; Eijsinga et al., 1973; Feigin and Sagiv, 1987; Smith et al., 1996, 1997, 1998; Stolk and Maaswinkel, 1977; Uffelen, 1973, 1975). Certain environmental stressors seem to increase the incidence and severity of symptoms including high temperatures (Aloni et al., 1994; Feigin and Sagiv, 1987), shading in greenhouse environments (Aloni et al., 1994; Smith et al., 1996, 1997), macronutrient application rates including foliar calcium sprays and nitrogen applications (Aloni et al., 1994; Feigin and Sagiv, 1987; Smith et al., 1996, 1997, 1998); furthermore, elevated calcium carbonate soil nutritional status has been reported as a factor leading to symptom expression (Carroll, 1979; Eijsinga et al., 1973).

Shading. A relationship between low lighting conditions and the increased incidence and severity of stip has been suggested (Aloni et al., 1994; Smith et al., 1996, 1997). To test the possibility of a relationship between shading, nitrogen fertilization, and symptom manifestation, Aloni et al. (1994) conducted a series of experiments with three different bell pepper cultivars, Maor, Lady Bell, and 899, with increasing stip resistance, respectively. These plants were then grown under fully exposed or shaded environments (a black shading net reduced midday photosynthetic available radiation from $1400 \mu \mathrm{mol} \cdot \mathrm{m}^{-2} \cdot \mathrm{s}^{-1}$ to 700) with three different levels of nitrogen fertilization $\left(0,100,250 \mathrm{mg} \cdot \mathrm{L}^{-1}\right)$. When the plants were fully exposed to sunlight with no nitrogen fertilization, $17 \%$ of fruit of the susceptible cultivar, Maor, developed stip symptoms. However, when the plants were in light-limited conditions with no nitrogen fertilization, the amount of symptomatic fruit rose to $43 \%$. Similarly, but less pronounced, the moderately resistant cultivar, Lady Bell, had no symptomatic fruit when the plants were fully exposed to light, but $3 \%$ when the plants were exposed to a reduced light environment.

Support for the importance of light levels as a stip factor comes from field reports produced in California with bell peppers by Smith et al. (1996, 1997, 1998, 1999). During several years of study, Smith et al. saw a consistent pattern wherein, production areas that experienced diminished levels of light exposure (a consequence of unusually shorter seasons, and hence shorter daylengths) showed a greater incidence and severity of stip than would otherwise be expected (Smith et al., 1996, 1997, 1998).

Nitrogen: Macronutrient application rates. Increasing nitrogen application rates have shown a resulting increase in the percentage of stip symptomatic fruits (Aloni et al., 1994; Feigin and Sagiv, 1987). Feigin and Sagiv conducted a series of experiments that suggested a connection between increasing nitrogen fertilization rates and the incidence and severity of symptoms. In 1986, an open-field factorial experiment which consisted of four levels of soil fertilization [control - unfertilized field, cattle waste manure pellets $(0.006$ tons of pellets/ha), cattle waste manure pellets ( 0.018 tons/ha), and urban waste compost ( 0.03 tons/ha), combined with four different levels of nitrogen fertilizer $\left(0,0.13,0.26\right.$, and $\left.0.39 \mathrm{~kg} \cdot \mathrm{ha}^{-1}\right)$ applied directly to the bell pepper 'Maor' (the same cultivar used by Aloni et al. (1994)] was conducted in six replications. When the nitrogen fertilization rate was $0 \mathrm{~kg} \cdot \mathrm{ha}^{-1}$, there were no symptomatic fruit regardless of whether a manure treatment was applied, whereas with increasing amounts of nitrogen fertilizer the incidence percentage increased until it reached $97 \%$ of the total fruit at a nitrogen fertilization rate of $0.39 \mathrm{~kg} \cdot \mathrm{ha}^{-1}$ on soil with an urban waste compost application. Meanwhile the severity, number of lesions per fruit, showed a similar trend with increasing amounts of nitrogen fertilization. The study concluded that higher rates of nitrogen fertilization applications led to a statistically significant increase in both severity and incidence of stip in a susceptible cultivar under field conditions.

Aloni et al. (1994) completed a similar study, however, under greenhouse conditions, with two additional cultivars. 'Maor', 'Lady Bell', and '899', sequentially decreasing in susceptibility to both incidence and severity of stip, were grown and maintained in 10-L plastic containers, under three different levels of nitrogen fertilization $(0,100$, and $250 \mathrm{mg} \cdot \mathrm{L}^{-1}$ ), and unshaded or shaded environments. As the nitrogen concentration increased, the percentage of symptomatic fruit (in the susceptible or moderately resistant cultivars) also increased regardless of the lighting conditions. With no added nitrogen applications and under fully exposed conditions, 'Maor', produced $17 \%$ symptomatic fruit, and this percentage increased to $39 \%$ under the high $\left(250 \mathrm{mg} \cdot \mathrm{L}^{-1}\right)$ nitrogen application rate. When the plants were in light-limited conditions with no nitrogen application, the cultivar had $43 \%$ affected fruit, which increased to $70 \%$ under the high $\left(250 \mathrm{mg} \cdot \mathrm{L}^{-1}\right)$ nitrogen application rate. A similar trend was observed in the moderately resistant cultivar, Lady Bell. With no nitrogen applications and under fully exposed conditions, 'Lady Bell' did not produce symptomatic fruit. This percentage increased to $3 \%$ under the high $\left(250 \mathrm{mg} \cdot \mathrm{L}^{-1}\right)$ nitrogen application rate. When 'Lady Bell' peppers were in light-limited conditions with no nitrogen application, the cultivar had $3 \%$ affected fruit which increased to $6 \%$ symptomatic fruit under the high ( 250 $\mathrm{mg} \cdot \mathrm{L}^{-1}$ ) nitrogen application rate.

Although nitrogen applications appear to be an important contributing factor to stip symptom expression, there also appears to be an interaction with multiple environmental conditions so that generally more than one stressor is necessary for the development of the disorder. For example, Smith et al. (1997) examined the consequences of increasing nitrogen fertilization on the incidence and severity of stip in bell peppers 
Table 2. Pepper cultivar impact on yield, fruit weight, susceptibility to stip, and location of reported work.

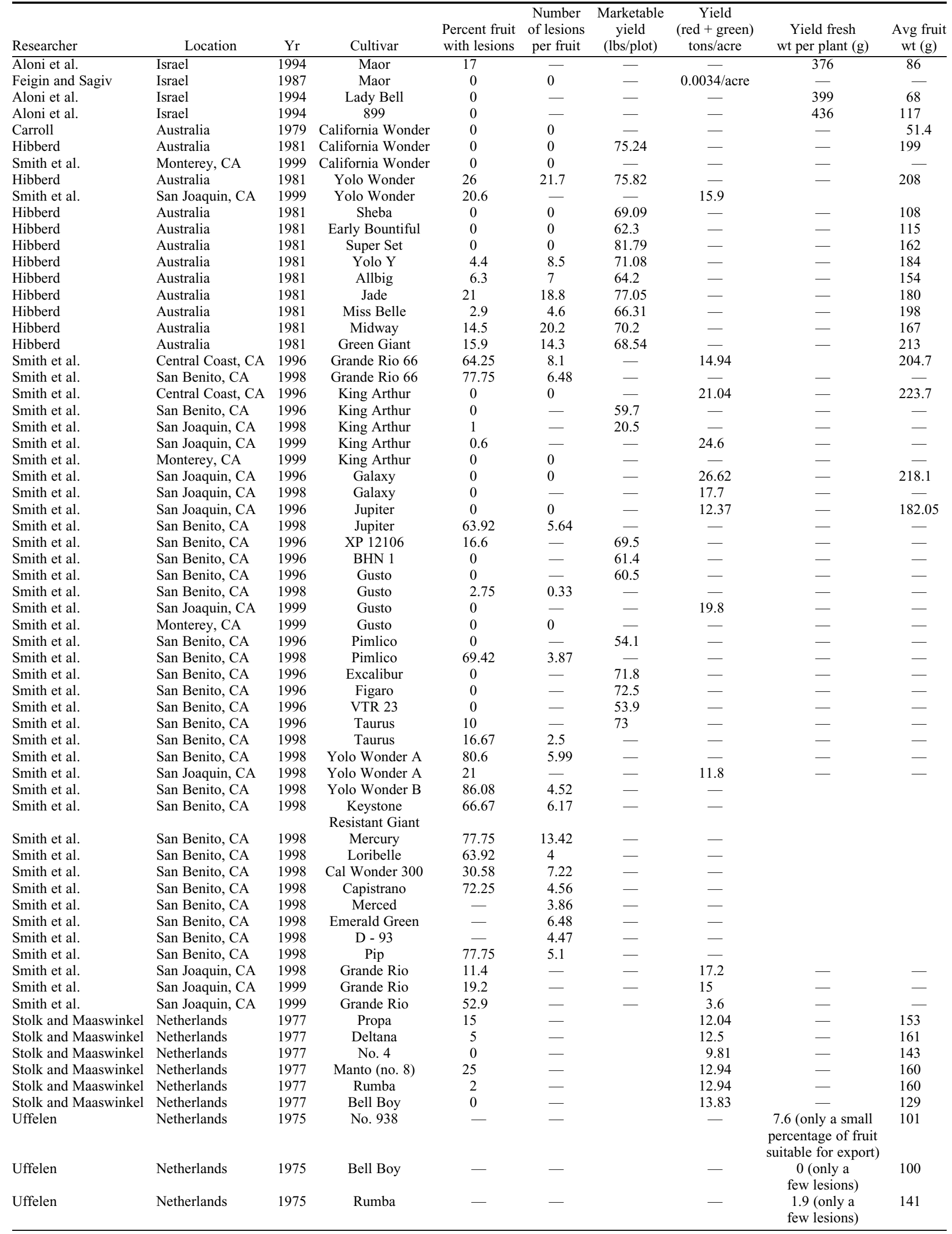


Table 2. (Continued) Pepper cultivar impact on yield, fruit weight, susceptibility to stip, and location of reported work.

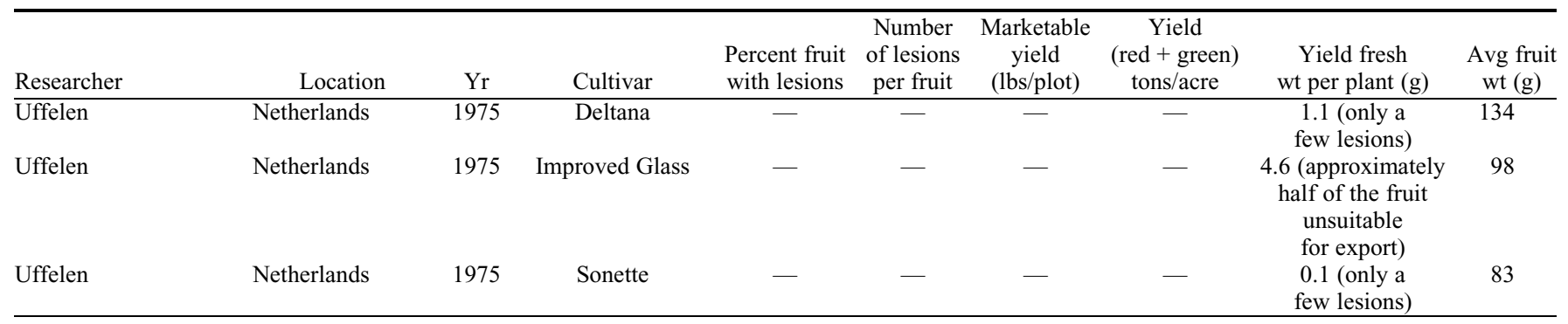

In designed experiments, values pertaining to the control treatment were used.

under field conditions. The authors did not report any significant differences in symptom development in the high fertilization rates compared with the medium and low treatments.

These studies suggest a relationship between increased symptom manifestation and high nitrogen fertilization. Although a specific quantitative threshold for symptom development is unknown, two studies appear to have induced symptoms through the use of nitrogen fertilization (Aloni et al., 1994; Feigin and Sagiv, 1987). Additionally, it appears that other environmental factors also contribute to initiation of the disorder.

Calcium: Macronutrient application rates. Five separate experiments conducted over a span of decades (1973-2000) have gone into testing whether calcium applications (either preplant gypsum or foliar calcium sprays) can prevent or reduce the incidence or severity of stip in the field and greenhouse. Smith et al. conducted a cultivar study in 1995 to test different cultivar's susceptibility to stip and noticed that the fields that were most heavily affected coincided with areas that were characterized as having soils with relatively low amounts of calcium and/or had received high fertilization applications (Smith et al., 1995). This observation led to the hypothesis that calcium sprays might have a preventative effect on symptom development. Consequently, in 1996, a series of experiments were conducted at four different sites (three in the Central Coast and one in San Joaquin County, CA) using the bell pepper cultivars Grande Rio 66 (susceptible) and King Arthur (resistant). At these test sites, both cultivars were field planted in experimental plots and $0,446.6$, and $893.18 \mathrm{~kg} \cdot \mathrm{ha}^{-1}$ of calcium in the form of 0,1 , and 2 tons of gypsum were applied as preplanting treatments. Additionally, a total of $2.61 \mathrm{~kg} \cdot \mathrm{ha}^{-1}$ of calcium nitrate were applied during the course of the experiment. At the San Joaquin sites, calcium sprays began during fruit bulking when pods were intermediate in size and continued until harvesting, whereas at the Central Coast sites, calcium sprays began at first flower and continued until harvest. At the San Joaquin site, no stip was reported that year while neither preplant gypsum applications, calcium nitrate sprays, nor a combination of either reduced the incidence of pepper stip in the two tested cultivars under the field conditions found at the Central
Coast. In 1998, Smith et al. again conducted a series of foliar calcium spray experiments to examine whether calcium applications reduced the incidence and severity of the disorder in field grown bell peppers. At the San Joaquin sites, calcium sprays began during fruit bulking when pods were small to intermediate in size and continued until harvesting, whereas at the San Benito sites, calcium sprays began at first flower and continued until harvest.

In San Joaquin County, CA, the low level $\left(2.34 \mathrm{~L} \cdot \mathrm{ha}^{-1}\right)$ of the foliar calcium application Cal Max, a suspension fertilizer with $22.5 \%$ calcium, reduced stip incidence in Grande Rio by $40.4 \%$ and in Yolo Wonder A by $62.4 \%$. The high level $\left(4.68 \mathrm{~L} \cdot \mathrm{ha}^{-1}\right)$ reduced incidence in Grande Rio by $85.1 \%$ and in Yolo Wonder A by $59.1 \%$. No statistical significance was reported for the calcium sprays at the San Benito sites. In 1999, Smith et al. repeated the foliar calcium application study in San Joaquin County, CA, using the cultivars Gusto, King Arthur, Grande Rio, and Yolo Wonder A with application sprays beginning when fruit pods were intermediately sized. Despite reporting between $18.6 \%$ and $23.3 \%$ fruit of a plant as affected, they reported no reduction in either the incidence or severity of stip (Mullen et al., 2000; Smith et al., 1999). Given the paucity of consistent results indicating that foliar calcium application treatments are effective generally or during specific growth periods, it would seem that they have little effect on preventing the disorder's manifestation. In addition to direct foliar calcium applications, researchers have examined the effect of soil calcium nutrient status in relation to symptom development (Carroll, 1979; Eijsinga et al., 1973) (Table 3).

In 1973, Eijsinga et al. conducted an experiment to test the effect of various soil constituents on the incidence and severity of stip. This study examined the effect of different potting materials and soil amendments on the development of stip symptoms in plants grown under greenhouse conditions. The results indicated that potting materials composed of calcium carbonate were a significant disorder inducer, whereas potassium and magnesium were equally significant disorder inhibitors. They noted that there was a significant correlation between the existence of magnesium and potassium in the potting soil used $(r=0.67)$. Although the contribution of these two elements was not examined in- dividually, the authors suggested that a monovalent ion, and potassium in particular, inhibits calcium more effectively than divalent magnesium led to the conclusion that potassium was the primary disorder inhibitor, and hence, suggesting that too much calcium was the cause of the disorder.

The effects of lime (calcium carbonate) and gypsum (hydrous calcium sulfate, $\mathrm{CaSO}_{4}$. $2 \mathrm{H}_{2} \mathrm{O}$ ) on stip manifestation were performed under greenhouse conditions (Carroll, 1979). In the first study in this report, the effect of lime soil treatments on the incidence and severity of stip symptoms in greenhouse grown plants was examined. These plants were established in a randomized block pot trial with four different lime treatments $(0,4$, 8,16 tons of total material applied/ha) with 12 replicates at each level. As the amount of lime increased the $\mathrm{pH}$ was raised from 4.2 to 7.5 , which coincided with the number of symptomatic fruit consistently increasing from $0 \%$ in the control to $36.9 \%$ in the high treatment (16 tons/ha). In the same report, a separate study examined the relationship between gypsum and lime in a randomized block pot greenhouse trial with five different treatments and 10 replications at each level (control, $2.5 \mathrm{t} \cdot \mathrm{ha}^{-1}$ lime, $5.0 \mathrm{t} \cdot \mathrm{ha}^{-1}$ lime, $2.5 \mathrm{t} \cdot \mathrm{ha}^{-1}$ gypsum, and $5.0 \mathrm{t} \cdot \mathrm{ha}^{-1}$ gypsum). The major difference between these calcium treatments was that the lime treatments had the effect of increasing the soil $\mathrm{pH}$ from 4.5 to 6.5 , whereas the $\mathrm{pH}$ remained constant at 4.5 with the gypsum treatments. The lime treatments at $2.5 \mathrm{t}$ of total material applied/ha had the highest percentage of affected fruit (slightly higher than the $5.0 \mathrm{t}$ of total material applied/ha treatment), whereas the $5.0 \mathrm{t}$ of total material applied/ha treatment of gypsum resulted in no symptom development. The author made no suggestion as to the relationship between these factors and symptom development.

\section{Tissue Analysis}

Calcium. In comparisons made between asymptomatic bell pepper fruit tissue and symptomatic fruits, calcium has been identified as a possible indicator of underlying biochemical mechanisms leading to the expression of the disorder (Eijsinga et al., 1973; Hibberd, 1981). Eijsinga et al. (1973) observed that symptomatic fruits contain more calcium than healthy fruit. Specifically, healthy mature, red fruit contained $0.09 \%$ 


\begin{tabular}{lccccc}
\hline & $\begin{array}{c}\text { Healthy } \\
\text { plant }\end{array}$ & $\begin{array}{c}\text { Healthy } \\
\text { pod }\end{array}$ & $\begin{array}{c}\text { Symptomatic } \\
\text { pod }\end{array}$ & $\begin{array}{c}\text { Healthy tissue, } \\
\text { symptomatic } \\
\text { pod }\end{array}$ & Stip \\
\hline Aloni et al. (1994) & NA & NA & NA & 0.0095 & 0.0315 \\
Carroll (1979) & 0.065 & NA & 0.117 & NA & NA \\
$\begin{array}{l}\text { Uchanski } \\
\quad \text { (unpublished data) }\end{array}$ & NA & 0.095 & NA & NA & 0.13 \\
Eijsinga et al. (1973) & NA & 0.09 & 0.15 & NA & NA \\
Hibberd (1981) & NA & Low & High & Higher & Highest \\
Soto-Ortiz (2008) & 0.2 & NA & NA & NA & NA \\
Smith et al. (1996) & NA & NA & NA & 0.09 & 0.32 \\
\hline NA & & & & & \\
\hline
\end{tabular}

$\mathrm{NA}=$ not applicable.

${ }^{\mathrm{z}}$ If the quantitative value is not known then the relative value was used.

calcium of dry matter, whereas symptomatic mature red fruit contained $0.15 \%(P<0.01$; Table 3$)$. The observation that symptomatic fruits had higher concentrations of calcium than asymptomatic fruits was also reported by Hibberd (1981). Furthermore, other researchers have reported that lesions had a higher amount of calcium than surrounding healthy tissue of the same symptomatic pod (Aloni et al., 1994; Hibberd, 1981; Smith et al., 1996).

Aloni et al. (1994) also reported the calcium concentration differences for the cultivars Maor and Lady Bell. Lesions of 'Maor' had a fresh weight calcium concentration of $0.037 \%$, whereas surrounding healthy tissue had a concentration of $0.01 \%$. Lesions on 'Lady Bell' had a concentration of $0.026 \%$ vs. $0.009 \%$ found in the surrounding healthy tissue. Aloni et al. also reported the observation made during the nitrogen and shading experiment that the susceptible cultivar Maor showed a decrease in leaf calcium content under increasing nitrogen applications (17.0 $\mathrm{mg} \cdot \mathrm{g}^{-1}$ fresh weight in leaves of control plants vs. $5.0 \mathrm{mg} \cdot \mathrm{g}^{-1}$ in stip plants grown with 250 $\mathrm{mg} \cdot \mathrm{L}^{-1}$ of nitrogen under full light conditions). Plants grown with shading had further decreases in leaf calcium $\left(6.6 \mathrm{mg} \cdot \mathrm{g}^{-1}\right.$ fresh weight in the control vs. $4.7 \mathrm{mg}^{-1}$ in stip grown plants with $250 \mathrm{mg} \cdot \mathrm{L}^{-1}$ of nitrogen under shaded light conditions). However, shading did not have a significant effect on fruit calcium content. Lastly, Smith et al. (1996) performed a similar analysis and found that the concentration of calcium in lesions was $0.32 \%$, whereas this concentration dropped to $0.09 \%$ in the surrounding healthy tissue (status of tissue, fresh or dry, is unknown).

Oxalic acid. Oxalic acid is a well-studied organic acid with multiple roles in plant physiology. Its role has been studied in various localized plant processes including intercellular communication, sequestration of excess calcium, and programmed cell death (Kim et al., 2008; Kostman et al., 2001). Therefore, when during the experiments conducted by Aloni et al. (1994) it was found that only fruits of the susceptible cultivar, Maor, showed a 9-fold increase in oxalate concentration upon increasing the nitrogen application rates under shaded conditions, this compound was further scrutinized for possible interaction with stip manifestation. Specifically, a $475 \%$ increase ( $0.16 \mathrm{mg}$ of fresh weight to $0.76 \mathrm{mg}$ of fresh weight) in oxalic acid $\left(\mathrm{H}_{2} \mathrm{C}_{2} \mathrm{O}_{4}\right)$ in these fruits was noted when nitrogen application rates were increased under shaded conditions. A similar but less pronounced increase from 0.42 to $0.52 \mathrm{mg}$ of fresh weight occurred under lighted conditions. On examination of lesions, Aloni et al. reported a distinct microscopic phenotype as compared with asymptomatic tissue. Specifically, crystalline structures were reported which were hypothesized to be calcium oxalate $\left(\mathrm{CaC}_{2} \mathrm{O}_{4}\right)$ crystals. This suggestion was based on the finding that oxalic acid increased only in the susceptible cultivar, Maor, and the observation that lesions contained a higher concentration of calcium than surrounding asymptomatic tissue. It was proposed that this might occur with the increasing nitrogen fertilization rates because the plant possibly produced a high content of oxalic acid to counterbalance and lower the increase in cytosolic $\mathrm{pH}$ due to the increased intracellular nitrogen concentration. It was hypothetically concluded that these calcium oxalate crystals then punctured the plant cells wherein they were found leading to subsequent cell death and oxidation (Aloni et al., 1994).

\section{Conclusions}

The disorder known as stip has been observed worldwide over the past several decades, and therefore poses a potential negative economic threat to the American pepper industry. This possibility merits a continued study of the disorder to identity the cause and methods for preventing its development. Based on the available literature, it appears that stip symptom manifestation is a consequence of an interaction between a genetic component (open-pollinated cultivars being more susceptible to symptom expression than hybrids) and an environmental component (increased nitrogen application, shading, and soil applications of lime appear to increase both severity and incidence). Suggested future research endeavors include testing for the effect of transpiration rate and anatomical characteristics on stip incidence and severity, a factorial study examining timings of calcium sprays during different physiological growth stages and levels of lime application, and analyzing stip lesions similarities and differences across pod type and cultivars. Especially because research into this disorder is scarce, it is essential that any and all previous research be made available together in one document to interested scientists, breeders, and growers.
Aloni, B., L. Rylski, and Z. Zaidman. 1994. The effect on nitrogen fertilization and shading on the incidence of "colour spots" in sweet pepper (Capsicum annuum) fruit. J. Hort. Sci. 69:767-773.

Carroll, E.T. 1979. Capsicum green spotting trial. Austral. Veg. Res. Nwsl. 37:37-38.

Eijsinga, R., R. Rodenburg, and L.G. Uffelen. 1973. Bitter pit, a new quality problem in red peppers (in Dutch). Bedrijfsontwikkeling. 4(7/8):733-734

Feigin, A. and B. Sagiv. 1987. Excessive nitrogen fertilization enhances "colour spots" in pepper fruits (in Hebrew). Hassadeh. 67(8):1564-1566.

Hibberd, A.M. 1981. Symptoms of and variety reaction to green pitting, a non-pathological disorder of red bell peppers in Queensland. Queensland J. Agr. Animal Sci. 38(1):47-53.

Kim, K., J.-Y. Min, and M. Dickman. 2008. Oxalic acid is an elicitor of plant programmed cell death during Sclerotinia sclerotiorum disease development. Mol. Plant-Microbe Interactions. 21:605-612.

Kostman, T., N. Tarlyn, F. Loewus, and V. Franceschi. 2001. Biosynthesis of 1-ascorbic acid and conversion of carbons 1 and 2 of 1-ascorbic acid to oxalic acid occurs within individual calcium oxalate crystal idioblasts. Plant Physiol. 125:634-640.

Mullen, R., J. Valencia, T. Viss, S. Whiteley, D. Brunmeier, W. Rogers, M. Rego, C. Cancilla, J. Noriega, and V. Sanchez. 2000. Bell pepper evaluation trials in California's Northern San Joaquin Valley. National Pepper Conference. 16.

North Carolina State University. 1996. Vegetable cultivar descriptions for North America. Pepper (A-Z). Paul W. Bosland (ed.).

Seminis. 2015. Stip. 6 Jan. 2016. <http://www.seminis-us. com/resources/disease-guides/pepper-eggplant/ $\operatorname{stip} />$.

Smith, R., B. Mullen, and T. Hartz. 1995. Epidemiology and control of pepper stip. CA. Pepper Comm., Dinuba, CA (abstr.).

Smith, R., B. Mullen, and T. Hartz. 1996. Epidemiology and control of pepper stip. CA. Pepper Comm., Dinuba, CA.

Smith, R., B. Mullen, and T. Hartz. 1997. Epidemiology and control of pepper stip. CA. Pepper Comm., Dinuba, CA.

Smith, R., B. Mullen, and T. Hartz. 1998. Epidemiology and control of pepper stip. CA. Pepper Comm., Dinuba, CA

Smith, R., B. Mullen, and T. Hartz. 1999. Epidemiology and control of pepper stip. CA. Pepper Comm., Dinuba, CA.

Soto-Ortiz, R. 2008. Crop phenology, dry matter production, and nutrient uptake and partitioning in cantaloupe (Cucumis melo L.) and chile (Capsicum annuum L.). Univ. of Ariz., Tucson, PhD Diss. 1-173.

Stolk, J.H. and R.H.M. Maaswinkel. 1977. Cultivars of autumn red pepper (in Dutch). Groenten en Fruit 32(39):1943.

Uffelen, L.G. 1973. Spotting (pitting), a quality problem in capsicums (in Dutch). Tuinderij 13(12):16-17.

Uffelen, L.G. 1975. Capsicums: Which variety for autumn culture? (in Dutch). Groenten en Fruit 30(40): 1860-1861.

Villalon, B. 1975. Black spot: A non-parasitic disease of bell pepper fruit in the lower Rio Grande Valley of Texas. Plant Dis. Rptr. 59(11):926-927.

Wien, H.C. and T.A. Zitter. 2003. Color spotting, p. 53-54. In: K. Pernezny, P.D. Roberts, J.F. Murphy, and N.P. Goldberg (eds.). Compendium of pepper disease. Amer. Phytopathol. Soc. Press, St. Paul, MN. 